Kong. Res. J. 3(1) : 84-87, 2016

ISSN 2349-2694

Kongunadu Arts and Science College, Coimbatore.

\title{
SCIENTOMETRIC ANALYSIS OF ASTROPHYSICS RESEARCH OUTPUT IN INDIA
}

\author{
Senthilkumar, $\mathbf{R}^{\mathbf{1}^{*}}$, and G. Ulaganathan ${ }^{2}$ \\ ${ }_{1}^{1}$ Librarian (SG) \& Head(Research), Department of Library and Information Science, Kongunadu Arts \& \\ Science College (Autonomous), Coimbatore-641029. \\ ${ }^{2}$ Librarian, Dr.SNS.Rajalakshmi College of Arts \& Science (Autonomous), Coimbatore-641 049. \\ *E.mail: kasclibrary@yahoo.com
}

\begin{abstract}
Astrophysics is a branch of space science that applies the laws of physics and chemistry to explain the birth, life and death of stars, planets, galaxies, nebulae and other objects in the universe. Astrophysics creates physical theories of small to medium-size structures in the universe. Astrophysicists seek to understand the universe and our place in it. At NASA, the goals of astrophysics are "to discover how the universe work, explore how it began and evolved, and search for life on planets around other stars." This study analyzes the Astrophysics research output in India from the year 1989-2014. The data was downloaded from web of science database which was maintained by Thomson Reuters. The findings of the study revealed that two authors has the maximum of contribution with 3673 (28.81\%) publication followed by three authors with $2875(22.55 \%)$.
\end{abstract}

Keywords: Scientometrices, Web of Science, Astrophysics. Histcite, Authorship pattern.

\section{INTRODUCTION}

Scientometric study is a statistical method of counting to evaluate and quantify the growth of a subject. The research trend during the said time span would be clearly understood from this study and a predictive projection may be made for anticipatable future. There are several areas in science, social science and arts for which scientometric studies were carried out. A number of studies have been accomplished to evaluate research output and productivity in different areas of physics. In 2009, Kumara (2009) carried out scientometric studies in major areas of physics and engineering sciences. Some other scientometric studies in different subject domains include Jain and Garg (1992) (Laser research), Kademani (2006) (Thorium research), Stanhill (2001) (climatology), Garg and Padhi (1998) (Laser patent literature), Upadhye (2004) (physics Noble lectures), Lee (2003) (molecular and cell biology), Schummer (1997) (chemistry), Braun et al. (2000) and Gupta (1999) (Fullerene research) et al. A number of scientometric studies in the areas of astronomy and astrophysics have also been executed. Basu and Lewison (2005) evaluated research output of global astronomy and astrophysics by an analysis of papers in the Science Citation Index identified with a special filter and found out leading Indian institutions and authors. Jamali and Nicholas (2010) attempted scientometric analysis from a new angle. The results presented by him revealed interdisciplinary differences within physics and astronomy in terms of reading behaviour. Leta (2005) executed a comparative analysis of Brazilian research trend in astronomy, immunology and oceanography. Davoust and Schmadel (1969) studied publishing activities of the astronomers since 1969. Fernández (1998) studied transitional steps from individual science to collectivization in astronomy during twentieth century. Uzun and Ozel (1996) studied publication pattern of Turkish astronomers. Marx and Bornmann (2009) showed the transition from the static view of the universe to the big bang theory in cosmology through citation analysis. Sen (2004) discussed definition and scope of scientometrics for all major science subjects in the context of web resources (cybermetrics).

\section{Objectives}

$>$ To analyze the year wise publication of Astrophysics research output in India.

$>$ To analyze the Half period comparison.

$>$ To find out the Authorship pattern.

$>$ To determine the Document wise distribution of publication.

\section{MATERIALS AND METHODS}

The data for the study were retrieved from web of science database which is a scientific and indexing service maintained by Thomson Reuters. The Astrophysics research output of India was 
analyzed. The bibliographic details such as Astrophysics research ouput,authors, document types etc. were analyzed using Histcite which is a software package used for bibliometric analysis and information visualization.

\section{ANALYSIS}

A total of 12750 astro physics records were published in India. The research output was analyzed using various scientometric indicators.

\subsection{Yearwise publications}

Table 1. Year wise distribution of astrophysics research output

\begin{tabular}{|c|c|c|c|c|}
\hline S.No. & $\begin{array}{c}\text { Publication } \\
\text { year }\end{array}$ & RECS & TLCS & TGCS \\
\hline 1. & 1989 & 320 & 572 & 2361 \\
\hline 2. & 1990 & 377 & 758 & 3434 \\
\hline 3. & 1991 & 383 & 702 & 3616 \\
\hline 4. & 1992 & 331 & 554 & 2804 \\
\hline 5. & 1993 & 389 & 963 & 4904 \\
\hline 6. & 1994 & 369 & 985 & 5997 \\
\hline 7. & 1995 & 285 & 878 & 4245 \\
\hline 8. & 1996 & 300 & 977 & 6688 \\
\hline 9. & 1997 & 355 & 884 & 5200 \\
\hline 10. & 1998 & 323 & 904 & 6647 \\
\hline 11. & 1999 & 333 & 900 & 5297 \\
\hline 12. & 2000 & 355 & 1011 & 6967 \\
\hline 13. & 2001 & 423 & 1042 & 7771 \\
\hline 14. & 2002 & 422 & 992 & 11018 \\
\hline 15. & 2003 & 400 & 1113 & 10796 \\
\hline 16. & 2004 & 395 & 1035 & 9109 \\
\hline 17. & 2005 & 418 & 1080 & 8766 \\
\hline 18. & 2006 & 554 & 1543 & 12066 \\
\hline 19. & 2007 & 566 & 1009 & 8861 \\
\hline 20. & 2008 & 625 & 1034 & 9813 \\
\hline 21. & 2009 & 647 & 1133 & 10575 \\
\hline 22. & 2010 & 691 & 865 & 9049 \\
\hline 23. & 2011 & 795 & 657 & 9055 \\
\hline 24. & 2012 & 885 & 483 & 6902 \\
\hline 25. & 2013 & 913 & 324 & 4342 \\
\hline \multirow[t]{2}{*}{26.} & 2014 & 896 & 88 & 3287 \\
\hline & Total & 12750 & 22486 & 179570 \\
\hline
\end{tabular}

Table 1 shows the year wise distribution of Astrophysics research output in India from the year 1989-2014. A total of 12750 records were published during the given period. The highest number of publications is in the year 2013 with 913 records, having a Global Citation score 4342 and Local
Citation Score of 324,followed by 896 papers in the year 2014 with Global Citation score of 3287 and a Local Citation Score of 88. The year 2006 has scored the maximum Global Citation Score of 12066 with 554 publications. The lowest number of publications is in the year 1995 with 285 records, having a Global Citation Score of 878.It is also observed from the table that even minimum numbers of records have scored higher Global Citation Scores.

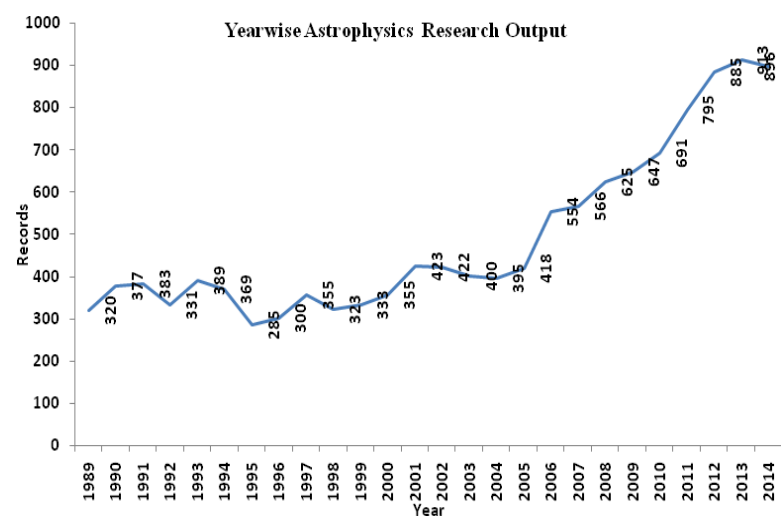

4.2. Half period comparison

Table 2. Half Period Comparison

\begin{tabular}{cccc}
\hline Period & $\begin{array}{c}\text { Average } \\
\text { Records }\end{array}$ & $\begin{array}{c}\text { Average } \\
\text { TLCS }\end{array}$ & $\begin{array}{c}\text { Average } \\
\text { RGCS }\end{array}$ \\
\hline $\begin{array}{c}\text { I Half } \\
\text { (1989- }\end{array}$ & 350 & 856 & 5072 \\
2001) & & & \\
II Half & & 874 & 8741 \\
(2002- & 631 & & \\
2014) & & & \\
\hline
\end{tabular}

The above table shows that in the second half period more number of articles is published compare to first half period. It shows growth rate of astrophysics research output in India.

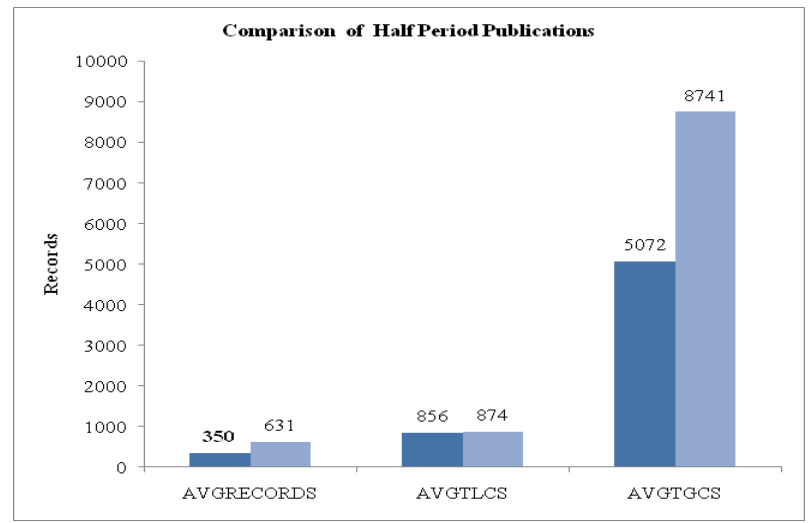


4.3. Authorship pattern of astrophysics research output

Table 3. Authorship pattern of astrophysics research output

\begin{tabular}{clcc}
\hline S.No. & \multicolumn{1}{c}{$\begin{array}{c}\text { Authorship } \\
\text { Pattern }\end{array}$} & $\begin{array}{c}\text { No. of } \\
\text { Publications }\end{array}$ & \% \\
1. & Single Author & 1817 & 14.25 \\
2. & Two Author & 3673 & 28.81 \\
3. & Three Author & 2875 & 22.55 \\
4. & Four Author & 1577 & 12.37 \\
5. & Five Author & 766 & 6.01 \\
6. & Six Author & 355 & 2.78 \\
7. & Seven Author & 218 & 1.71 \\
8. & Eight Author & 127 & 1.00 \\
9. & Nine Author & 101 & 0.79 \\
10. & Ten Author & 58 & 0.45 \\
11. & More than Ten & 1183 & 9.28 \\
\hline \multicolumn{3}{r}{ Author } & \multicolumn{2}{c}{ Total } & 12750 & 100 \\
\hline
\end{tabular}

The above table indicates authorship pattern of Astrophysics research output by India from the period 1989-2014.It is clearly noticed from the table that two authors has the maximum of contribution with $3673(28.81 \%)$ publication. It is also noted that out of 12750 publications only $58(0.45 \%)$ publications are contributed by ten authors.

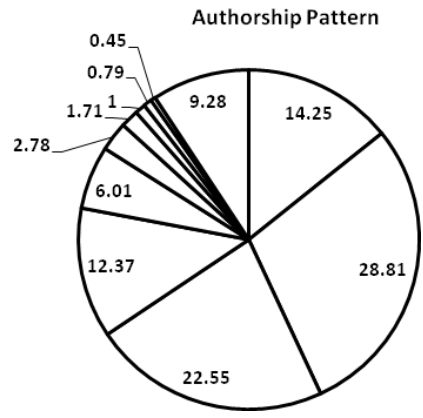

\subsection{Document types}

Table 4. Distribution of Document Types

\begin{tabular}{lccc}
\hline S.No Document Type & Recs & TLCS & TGCS \\
\hline 1. Article & 11389 & 20340 & 155123 \\
2. Article; Proceedings & 760 & 539 & 3458 \\
3. Letter & 193 & 462 & 2318 \\
4. Review & 177 & 930 & 17196 \\
5. Note & 134 & 198 & 1262 \\
6. Editorial Material & 46 & 2 & 99
\end{tabular}

\begin{tabular}{lccc} 
7. Correction & 38 & 5 & 69 \\
8. Reprint & 8 & 10 & 36 \\
9. Biographical-Item & 2 & 0 & 0 \\
10. Item About an & 1 & 0 & 1 \\
$\quad$ Individual & 1 & 0 & 0 \\
11. Meeting Abstract & 1 & 0 & 8 \\
12. Review; Book Chapter & 1 \\
\hline
\end{tabular}

The above table provides the distribution of publication on Astrophysics research by document types. It is clearly noticed from the table that the major source of publication in Astrophysics research comes in the form of articles with 11389 records, followed by proceedings paper and letter 760 and 193 publications respectively.

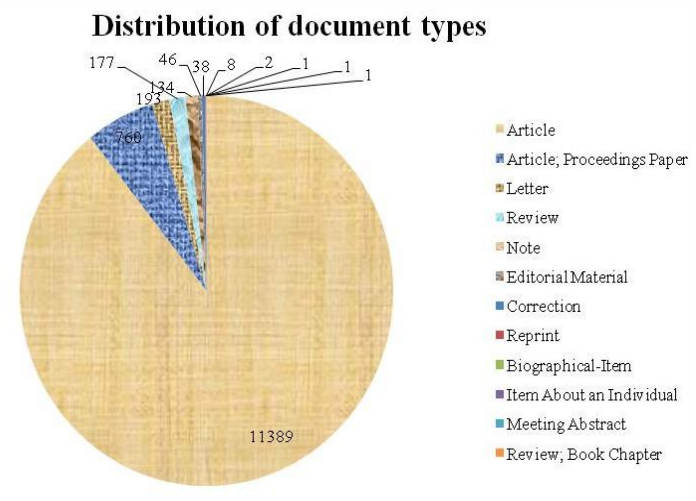

\section{CONCLUSION}

The Astrophysics research output in India as evidenced from the study has the highest publication of 913 papers in 2013 with 4342 Global Citation Scores followed by 896 papers in 2014 with 3287 Global Citation Score and 885 papers in 2012 with 6902 Global Citation Scores. The study shows that in the second half period average number of records is 631 with average Global Citation Score 8741 .It reveals that second half period (55\%) increase in average number of publications compare to the first half period. The majority of the articles are contributed by multiple authors. Especially Two authors' contribution is the highest among the other collaborative productivity. It indicates that the single authored work is less than that of the multiple authored contributions. The research has identified the factor; the three or two authored has been leading their research work to a winning triumph in the every year output in Astro physics. The major source of publication in Astrophysics research comes in the form of articles with 11389 records, followed by proceedings paper and letter 760 and 193 publications respectively. 


\section{REFERENCES}

Basu, A and G. Lewison, (2005). Going beyond journal classification for evaluation of research outputs: a case study of global astronomy and astrophysics research, Aslib Proceedings 57(3):232-246.

Braun, T., A.P. Schubert and R.N. Kostoff, (2000). Growth and trends of Fullerene research as reflected in Its journal literature, Chem. Rev. 100:23-37.

Davoust, E. and L.D. Schmadel, (1969). A study of the publishing activity of astronomers since 1969, Scientometrics 22(1):9-39.

Fernández, J.A., (1998). The transition from an individual science to a collective one: the case of astronomy, Scientometrics 42(1):61-74.

Garg, K.C. and P. Padhi, (1998). Scientometric study of LASER patent literature, Scientometrics 43(3):443-454.

Gupta, V.K., (1999). Technological trends in the area of Fullerenes using bibliometric analysis of patents, Scientometrics 44(1):17-31.

Jain, A. and K.C. Garg, (1992). LASER research in India: scientometric study and model projections, Scientometrics 23(3):395-415.

Jamali, H.R. and D. Nicholas, (2010). Intradisciplinary differences in reading behaviour of scientists: case study of physics and astronomy, The Elec. Lib. 28(1):54-68.

Kademani, B.S. (2006). World literature on thorium research: A scientometric study based on Science Citation Index, Scientometrics 69(2):347-364.

Kumara, A., (2009). Bibliometric and Scientometric Studies in Physics and Engineering: Recent Ten Years Analysis, In Putting Knowledge to Work: Best Practices in Librarianship, Mumbai (India).
Lee, C.K., (2003). A scientometric study of the research performance of the Institute of Molecular and Cell Biology in Singapore, Scientometrics 56(1):95-110.

Leta, J., (2005). Human resources and scientific output in Brazilian science: mapping astronomy, immunology and oceanography, ASLIB Proceedings, 57(3):217-231.

Marx, W. and L. Bornmann, (2009). How accurately does Thomas Kuhn's model of paradigm change describe the transition from the static view of the universe to big bang theory in cosmology? Scientometrics 84(2):441-464.

Schummer, J., (1997). Scientometric studies on chemistry I: the exponential growth of chemical substances, 1800-1995, Scientometrics 39(1):107-123.

Sen, B.K., (2004). Cybermetrics-Meaning, Definition, Scope and Constituents WIS-2004, International Workshop on Webometrics, Informetrics and Scientometrics,(eds.). Hildrun Kretschmer, Yogendra Singh, and Ramesh Kundra,. (2-5 March, 2004).Organised by Society for Information Science, New Delhi, and Indian Institute of Technology, Roorkee, India, pp. 310-315.

Stanhill, G., (2001). The growth of climate change science: a scientometric study, Climatic Change 48(2-3):515-524.

Upadhye, R.P., (2004). Scientometric analysis of synchronous references in the Physics Nobel lectures, 1981-1985: A pilot study, Scientometrics 61(1):55-68.

Uzun, A. and M.E. Ozel, (1996). Publication patterns of Turkish astronomers, Scientometrics 37(1):159-169. 